\title{
REASSESSMENT OF THE CLASSIFICATION OF BRYOPSIDALES \\ (CHLOROPHYTA) BASED ON CHLOROPLAST PHYLOGENOMIC
} ANALYSES

Ma. Chiela M. Cremen ${ }^{1}$, Frederik Leliaert ${ }^{2,3}$, John West ${ }^{1}$, Daryl W. Lam ${ }^{4}$, Satoshi Shimada $^{5}$, Juan M. Lopez-Bautista ${ }^{4}$, and Heroen Verbruggen ${ }^{1}$

${ }^{1}$ School of BioSciences, University of Melbourne, Parkville, 3010 Victoria, Australia

${ }^{2}$ Botanic Garden Meise, 1860 Meise, Belgium

${ }^{3}$ Department of Biology, Phycology Research Group, Ghent University, 9000 Ghent, Belgium

${ }^{4}$ Department of Biological Sciences, The University of Alabama, 35487 Alabama, U.S.A.

${ }^{5}$ Faculty of Core Research, Natural Science Division, Ochanomizu University, 2-1-1 Otsuka, Bunkyo, Tokyo 112-8610, Japan

\begin{abstract}
The Bryopsidales is a morphologically diverse group of mainly marine green macroalgae characterized by a siphonous structure. The order is eomprisedcomposed of three suborders - Ostreobineae, Bryopsidineae, and Halimedineae. While previous studies improved the higher-level classification of the order, the taxonomic placement of some genera in Bryopsidineae (Pseudobryopsis and Lambia) as well as the relationships between the families of Halimedineae remains uncertain. In this study, we re-assess the phylogeny of the order with datasets derived from chloroplast genomes, drastically increasing the taxon sampling by sequencing 32 new chloroplast
\end{abstract}


genomes. The phylogenies presented here provided good support for the major lineages (suborders and most families) in Bryopsidales. In Bryopsidineae, Pseudobryopsis hainanensis was inferred as a distinct lineage from the three established families allowing us to establish the family Pseudobryopsidaceae. The Antarctic species Lambia antarctica was shown to be an early-branching lineage in the family Bryopsidaceae. In Halimedineae, we revealed several inconsistent phylogenetic positions of macroscopic taxa, and several entirely new lineages of microscopic species. A new classification scheme is proposed, which includes the merger of the families Pseudocodiaceae, Rhipiliaceae and Udoteaceae into a more broadly circumscribed Halimedaceae, and the establishment of tribes for the different lineages found therein. In addition, the deep-water genus Johnson-sea-linkia, currently placed in Rhipiliopsis, was reinstated based on our phylogeny.

Keywords: siphonous green algae; seaweeds; chloroplast genome; phylogeny;

\section{Ulvophyceae}

\section{Introduction}

The order Bryopsidales (Chlorophyta) is a diverse group of mainly marine macroalgae. Species have a siphonous structure with the thallus consisting of a single giant tubular cell (siphon), which contains thousands of nuclei and chloroplasts that are transported throughout the cell by cytoplasmic streaming (Vroom and Smith, 2003). The group likely originated in the late Proterozoic or Cambrian and diversified into its component families during the Paleozoic and early Mesozoic (Verbruggen et al., 2009a). Extant species exhibit diverse morphologies ranging from simple branched siphons (Boodleopsis, Bryopsis, Caulerpa, Chlorodesmis, Derbesia, 
Pseudochlorodesmis, Ostreobium) to more complex, multiaxial thalli (Codium, Halimeda, Rhipilia, Rhipiliopsis, Udotea) (Lam and Zechman, 2006; Verbruggen et al., 2009a; Vroom et al., 1998). The Bryopsidales comprise about 564 species (Guiry and Guiry, 2017) distributed from tropical- to Arctic marine waters (Kerswell, 2006), with a single genus (Dichotomosiphon) found in freshwater habitats. They are among the major primary producers on both coral reefs and rocky shores, as well as in embayments, lagoons, and seagrass beds. Some tropical representatives have calcified thalli and are major contributors to coral reef formation (e.g. Halimeda mounds) (Drew and Abel, 1995; Drew, 1983). Species like Trichosolen are known to form blooms on coral reefs after physical damage has occurred, for instance from hurricanes or ship groundings (Pauly et al., 2011). Other species are notorious for their invasive nature, affecting the native biota in areas of introduction (e.g. Caulerpa taxifolia, Caulerpa racemosa var. cylindracea, and Codium fragile) (Klein and Verlaque, 2008; Meinesz et al., 2001; Trowbridge, 1995).

Hillis-Colinvaux (1984) introduced a subordinal classification for Bryopsidales, which is still in place today with some modifications. The suborder Bryopsidineae is characterized by homoplastidic thalli (with chloroplasts only), absence of a concentric lamellar system from the chloroplast (which plays a role in the initial synthesis and organization of the thylakoids; also called a thylakoid-organising body (Solymosi, 2013)), non-holocarpic reproduction (production of reproductive zooids occur within delimited zones of the thallus) with cross-walls commonly present at the base of reproductive structures, and cell walls made up of mannan or xylan, and cellulose. Halimedineae on the other hand are heteroplastidic (with both amyloplasts and chloroplasts), have a concentric lamellar system, feature holocarpic reproduction (all 
of the cytoplasm is transformed into reproductive cells, and their release results in the death of the parental siphonous thallus) without septa at the base of reproductive structures, and have cell walls predominantly made of xylan. A third lineage, Ostreobineae that includes a single genus, Ostreobium, was added by Verbruggen et al. (2017) mainly based on phylogenetic analysis of chloroplast genomes. The Ostreobineae have been much less studied morphologically than the other two groups. Species are endolithic in limestone substrate, and quadriflagellate zoospores produced in sporangia not separated by a cross-wall from the rest of the thallus have been reported for Ostreobium queketti (Kornmann and Sahling, 1980).

Vroom et al. (1998) inferred the phylogeny of Bryopsidales using morphological and anatomical features. Subsequent studies utilized chloroplast- and nuclear-encoded gene sequences to further characterise the higher-level phylogeny of the order (Lam and Zechman, 2006; Verbruggen et al., 2009a), its families (Kooistra, 2002; Woolcott et al., 2000) and genera (De Clerck et al., 2008; Draisma et al., 2014; Famà et al., 2002; Hillis et al., 1998; Krellwitz et al., 2001; Verbruggen et al., 2009b, 2007). A multi-locus molecular phylogeny of Bryopsidales recovered a well-supported, monophyletic Bryopsidineae (including families Bryopsidaceae, Codiaceae, and Derbesiaceae) and Halimedineae (including families Caulerpaceae, Dichotomosiphonaceae, Halimedaceae, Pseudocodiaceae, Rhipiliaceae, and Udoteaceae) (Verbruggen et al., 2009a). Within the Bryopsidineae, phylogenetic placement of the genera Pseudobryopsis, Trichosolen and Lambia has not been confidently determined. Two studies based on the $r b c \mathrm{~L}$ gene inferred Pseudobryopsis myura (syn.: Trichosolen myura) as sister to Bryopsis (Lam and Zechman, 2006; 
Woolcott et al., 2000) but with low support. No molecular data isare available for Lambia, and its placement within the Bryopsidineae is unknown.

Within the Halimedineae, the family Dichotomosiphonaceae has been recovered as sister to what was referred to the 'core Halimedineae' with high support (Verbruggen et al., 2009a). However, relationship between the families within the core Halimedineae (Caulerpaceae, Rhipiliaceae, Halimedaceae, Pseudocodiaceae, and Udoteaceae) remained poorly resolved in previous work.

A previous comprehensive phylogenetic study of the Bryopsidales was based on five genes (four plastid genes, $r b c \mathrm{~L}, t u f \mathrm{~A}, a t p \mathrm{~B}$, and $16 \mathrm{~S}$ rDNA, and the nuclear encoded 18S rDNA) (Verbruggen et al., 2009a). Since then, high throughput sequencing (HTS) methods have greatly aided the acquisition of large multi-locus datasets. Phylogenomic analyses based on chloroplast genome data have helped to resolve evolutionary relationships of several algal groups, including the red algae (Costa et al., 2016; Díaz-Tapia et al., 2017), and green algae (Fang et al., 2018; Lemieux et al., 2015, 2014a, 2014b; Turmel et al., 2017, 2008). Chloroplast genome data for Bryopsidales have been accumulating steadily in recent years (Cremen et al., 2018; del Campo et al., 2017; Lam and Lopez-Bautista, 2016; Leliaert and Lopez-Bautista, 2015; Lü et al., 2011; Marcelino et al., 2016; Verbruggen et al., 2017). The availability of these sequence data, manageable size of chloroplast genomes, conserved gene content ( $\sim 8$ protein-coding genes) of Bryopsidales (Cremen et al., 2018) and the non-recombinant nature of chloroplast genomes makes them useful tool for phylogenomic studies (Oliveira et al., 2018). 
This study aims to re-examine the classification of Bryopsidales based on chloroplast phylogenomic analysis with increased taxon sampling across all families.

Specifically, we aim to infer the position of Pseudobryopsis and Lambia within the Bryopsidineae and determine the relationship of different families within the Halimedineae.

\section{Materials and Methods}

\subsection{Taxon sampling and DNA extraction}

We selected 24 taxa from eight bryopsidalean families for chloroplast genome sequencing, along with six taxa of Dasycladales as a close outgroup to Bryopsidales (Verbruggen et al., 2017). Total genomic DNA was extracted from silica gel-dried or ethanol-preserved thallus fragments using a modified CTAB protocol described in Cremen et al. (2016). Lambia antarctica was field collected and frozen at $-80{ }^{\circ} \mathrm{C}$ and was extracted using DNeasy Plant Mini Kit (Qiagen, Hilden, Germany). Samples used in this study are listed in Supplementary Table S1.

\subsection{Sequencing, genome assembly, and annotation}

Library preparation and sequencing were performed either at Georgia Genomics Facility (University of Georgia, GA, USA), the Genome Center of Cold Spring Harbor Laboratory (NY, USA), or Novogene using Illumina sequencing platforms (Supplementary Table S1). Genome assembly followed Verbruggen and Costa (2015), Marcelino et al. (2016), and Lam and Lopez-Bautista (2016). In brief, de novo assembly was performed from the paired-end Illumina reads using four different assembly programs: 1) CLC Genomics Workbench 7.5.1, 2) SPAdes 3.8.1 
(Bankevich et al., 2012), MEGAHIT 1.0.6 (Li et al., 2014), and IDBA (Peng et al., 2010). Because one of the samples of the turf species Pseudochlorodesmis sp.

HV01306 turned out to contain multiple species, metagenome binning was carried out to separate the contigs from different species following Verbruggen et al. (2017). These analyses were done using contigs larger than $18 \mathrm{~kb}$ resulting from CLC and SPAdes assemblies and used MyCC (Lin and Liao, 2016) and MaxBin 2.2 (Wu et al., 2014). Annotation followed Verbruggen and Costa (2015), Marcelino et al. (2016), or Lam and Lopez-Bautista (2016). In addition to the data generated here, 30 complete or partial chloroplast genome sequences belonging to other members of Ulvophyceae were downloaded from GenBank and included in our analyses (Supplementary Table $\mathrm{S} 1)$.

\subsection{Alignments}

In order to assess the effect of outgroup selection on phylogenetic inference, three different datasets were generated. The first included only Bryopsidales without outgroups, called the Bryopsidales alignment. It is well known that analyses without an outgroup can yield more reliable (yet unrooted) ingroup trees (Shavit et al., 2007). In Bryopsidales, it has been established with strong confidence that Ostreobineae is sister to the remaining lineages of the order (Verbruggen et al., 2017), which facilitates rooting the Bryopsidales-only trees along the branch separating Ostreobineae from the rest of the order. The second dataset used the Dasycladales as outgroup, which was indicated to be related to Bryopsidales in previously published chloroplast and nuclear phylogenies (Cocquyt et al., 2010; Fučíková et al., 2014; Škaloud et al., 2013). This dataset is called the Bryopsidales-Dasycladales alignment. The third dataset used several other orders of the Ulvophyceae 
(Oltmannsiellopsidales, Ulvales, Ulotrichales, Ignatiales) as outgroups, and is called the Ulvophyceae alignment.

\subsection{Phylogenetic inference}

For each of the three datasets, alignments for each chloroplast protein-coding gene were inferred with TranslatorX (Abascal et al., 2010), which translates sequences to amino acids then performs multiple sequence alignment of the amino acid sequences with MAFFT v.7.3.9 (Katoh and Standley, 2013) to generate the corresponding nucleotide alignments. Resulting gene alignments were checked visually in Geneious 10.2.3. For those that could not be reliably aligned, GBlocks (which eliminates poorly aligned positions and divergent regions of DNA alignments) (Castresana, 2000) was used. If GBlocks removed $>60 \%$ of the alignment position for each individual gene, the entire gene was excluded from the phylogenetic reconstruction, leading to the complete removal of $f t s \mathrm{H}, r p o \mathrm{~A}, r p o \mathrm{~B}, r p o \mathrm{C} 1, r p o \mathrm{C} 2$, and $t i l \mathrm{~S}(=y c f 62)$ from all three datasets. In addition to these genes, $r p l 19, r p l 23, r p s 7$, rps 9 , and $y c f 1$ were excluded from the Bryopsidales-Dasycladales datasets. Additional genes such as $\operatorname{ccs} 1$, pet $\mathrm{L}$, rpl32, rps 18, ycf20, and $y c f 47$ were excluded from the Ulvophyceae dataset (Supplementary Table S2).Tables S2a and S2b).

For each of the three datasets, unpartitioned and partitioned analyses were carried out at both the amino acid and nucleotide level. Partitioning was done by gene for amino acid-level analyses and by codon position $\left(1^{\text {st }}+2^{\text {nd }}, 3^{\text {rd }}\right)$ for analyses at the nucleotide level. 
For all three unpartitioned datasets, analyses at the nucleotide level were carried out using a GTR $+\Gamma+$ I model based on the BIC criterion in jModelTest 2 (Darriba et al., 2012). At the amino acid level, analyses of all three unpartitioned datasets were carried out using CPREV $+\Gamma+\mathrm{I}+\mathrm{F}$ model based on the BIC criterion in ProtTest 3.4.1 (Darriba et al., 2011; Guindon and Gascuel, 2003). Model tests were also conducted for the partitioned dataset using ModelFinder (Kalyaanamoorthy et al., 2017) as implemented in IQ-Tree. Further analyses were carried out to assess the sensitivity of these analyses to model choice (LG, WAG), and with $\Gamma$ among-site rate variation and estimated AA frequencies on both partitioned and unpartitioned datasets (Supplementary Table S3). Due to extensive analyses with multiple alignments and multiple models of sequence evolution and partitioning strategies (48 analyses total) (Supplementary Table S3), we limited our analyses to maximum likelihood with RAxML 8.2.9, using 1,000 standard bootstrap replicates (Stamatakis, 2014).

\section{$2.518 S \mathrm{rDNA}$ sequences}

Nuclear encoded 18S rDNA sequences were also extracted from the assemblies. This was done using the BLAST plug-in in Geneious by creating a BLAST database of contigs and querying it with published $18 \mathrm{~S}$ sequences of bryopsidalean and dasycladalean taxa from GenBank (Supplementary Table S4). The result was set to: bin into 'hit' vs. 'no hit' settings. The contigs that gave hits were then annotated using the 'annotate from' function in Geneious using the reference 18S sequences. The resulting annotations were then exported and checked in NCBI BLASTN database to confirm if it they did indeed match to bryopsidalean taxa. Using this method, we were able to extract the $18 \mathrm{~S}$ rDNA sequences for most of the samples. 
18S rDNA sequences extracted from our samples and published bryopsidalean and dasycladalean 18S sequences were aligned in Geneious using MAFFT. Poorly aligned positions were removed using the GBlocks and a phylogenetic tree was inferred with maximum likelihood in RAxML using a GTR $+\Gamma+$ I model based on the BIC criterion in jModelTest 2 with 1,000 standard bootstrap replicates.

\section{Results}

\subsection{New chloroplast genomes}

We obtained 12 partial and 14 complete chloroplast genomes from Bryopsidales (GenBank: MH591079-MH591114, KT946603, KU059765) and 6 partial chloroplast genomes from Dasycladales (GenBank: MH545188MH545187-MH545361) representing all families from both orders. The variable structure (genome size, gene order, intron content) and conserved gene content of the new genomes were in line with those previously reported for the group (Cremen et al., 2018; Lam and LopezBautista, 2016; Leliaert and Lopez-Bautista, 2015; Verbruggen et al., 2017). Genome size, gene content, and various other features of the newly sequenced bryopsidalean taxa are listed in Supplementary Table S5. The assemblies of the five newly sequenced dasycladalean taxa failed to recover complete chloroplast genomes. Instead, the assemblies for Dasycladales samples recovered multiple contigs containing chloroplast genes from which we were able to recover between 10 and 36 chloroplast genes depending on the species (Supplementary Table S5). The Bryopsidales and Bryopsidales-Dasycladales alignments contained 71 and 66 genes from 42 and 50 taxa, respectively. The gene alignments were $95 \%$ filled in Bryopsidales and $87 \%$ in Bryopsidales-Dasycladales. The Ulvophyceae alignment 
contained 62 genes from 62 taxa and was $87 \%$ filled. The $18 \mathrm{~S}$ rDNA alignment was 1,185 bp long and included 80 species in total (65 ingroup species).

\subsection{Relationship between the three suborders of Bryopsidales}

Maximum likelihood (ML) phylogenetic inferences from the concatenated chloroplast gene datasets of both nucleotide and amino acid alignments resulted in well-supported phylogenies for Bryopsidales in all three datasets (Figure 1 and Supplementary FigureFigures S1-S3). Suborder Ostreobineae was inferred as sister to the clade containing the Bryopsidineae and Halimedineae with high support (92-100\%) regardless of outgroup sampling and analysis method.

In the suborder Bryopsidineae, the Derbesiaceae and Codiaceae were recovered as sister families with maximum support and these two families were recovered as sister to the Bryopsidaceae with maximum support in all analyses. Pseudobryopsis hainanensis, traditionally classified in the Bryopsidaceae, was inferred as sister to the three established families with low (58\%) to high (96\%) bootstrap support. A closer inspection of the bootstrap trees from different analyses showed that $P$. hainanensis was at times recovered as sister to Ostreobineae in the analyses that included outgroups (i.e. Bryopsidales-Dasycladales and Ulvophyceae datasets), or as sister to Bryopsidineae + Halimedineae (unrooted Bryopsidales only dataset). The Antarctic Lambia antarctica was shown to be an early-branching lineage of Bryopsidaceae with maximum support (Figure 1 and Supplementary FigureFigures S1-S3).

In the suborder Halimedineae, Dichotomosiphonaceae was recovered as sister to the core Halimedineae with maximum support. Within the core Halimedineae, the 
monogeneric family Caulerpaceae was monophyletic and always recovered as sister to the remaining lineages in the core Halimedineae with maximum support.

The remainder of the core Halimedineae contained seven lineages, and because there were several disagreements between the existing classification and these lineages, we have numbered them from 1 through 7 in Figure 1 for ease of reference. Only one of the existing families, the monogeneric Halimedaceae (lineage 5), was recovered as monophyletic, and for another, the Pseudocodiaceae (lineage 6), only a single species was included. The two other families in this radiation of lineages - Rhipiliaceae and Udoteaceae - were not monophyletic, and fragmented into several lineages. One of these (lineage 7) contained the bulk of the Udoteaceae genera (Flabellia, Tydemania, Udotea, Chlorodesmis) and was recovered with full support as sister to the Pseudocodiaceae. Three other Udoteaceae genera (Callipsygma, Boodleopsis and Pseudochlorodesmis) were recovered elsewhere in the tree (see below). The Rhipiliaceae were also scattered in the tree, with Johnson-sea-linkia profunda and Rhipilia penicilloides grouped in lineage 3-, while Rhipiliopsis peltata was recovered in lineage 4. These scattered taxa in the Rhipiliaceae and the Udoteaceae formed several early-branching lineages: (1) Boodleopsis sp. H.0758 (Udoteaceae); (2) Pseudochlorodesmis spp. HV01306a and HV01306c (Udoteaceae); (3) the clade containing Boodleopsis sp. FL1161, Boodleopsis pusilla, and Pseudochlorodesmis sp. HV01306b (Udoteaceae) along with Johnson-sea-linkia profunda and Rhipilia penicilloides (Rhipiliaceae); (4) Callipsygma wilsonis (Udoteaceae) + Rhipiliopsis peltata (Rhipiliaceae) clade.

While each of these early-branching lineages got solid support, the relationships 
between them were recovered with low to moderate support depending on the dataset and analysis technique (Figure 1 and Supplementary Figures S1-S3).

In spite of this variable support, several patterns regarding the relationships of clades in the core Halimedineae emerged from the different datasets and models used. First, Boodleopsis sp. H.0758 (lineage 1) was always the first to branch off. Second, the Callipsygma wilsonis + Rhipiliopsis peltata clade (lineage 4) was always recovered as sister to Halimeda (lineage 5), and Pseudocodium (lineage 6) was always recovered as sister to lineage 7. The Pseudochlorodesmis spp. HV01306a and HV01306c clade (lineage 2) was either sister to lineage 3 (Figure 2A), sister to the clade comprised of lineage $4+$ lineage 5 and $6+$ lineage 7 (Figure 2B), or sister to the clade comprised of: lineage $3+$ lineage $4+$ lineage 5 and lineage $6+$ lineage 7 (Figure 2C) depending on outgroup selection and model used (Supplementary Table S6).

\subsection{S rDNA phylogeny}

The nuclear 18S phylogeny (Supplementary Figure S4) recovered Ostreobineae as sister to Bryopsidineae + Halimedineae with maximum support. In the suborder Bryopsidineae, the Derbesiaceae was inferred as sister to the Bryopsidaceae + Codiaceae but bootstrap support for the latter was low (44\%). Similar to the chloroplast genome phylogeny, Pseudobryopsis was recovered as an early branching lineage sister to the three established families with maximum support. Lambia antarctica was similarly placed in the Bryopsidaceae where it is sister to Bryopsis + Pseudoderbesia.

In the suborder Halimedineae, the topology from the $18 \mathrm{~S}$ phylogeny was incongruent 
with the chloroplast genome phylogenies and the relationships among the different lineages inferred were very low (12 $-58 \%$ bootstrap support). The families Rhipiliaceae and Udoteaceae were again recovered in several lineages. Lineage 7 (based on chloroplast genome phylogenies), which contained the bulk of the Udoteaceae was split into 2 lineages. One lineage included Flabellia and Tydemania (Lineage 7a), and the other has Chlorodesmis, Penicillus, Rhipocephalus, and Udotea (Lineage 7b) (Supplementary Figure S4). The Rhipiliaceae was also recovered in two lineages with-Lineage 3 containingcontained most of the representatives of

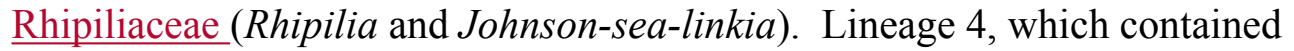
Callipsygma and Rhipiliopsis peltata based on chloroplast genome phylogeny, was also split into 2 lineages. Callipsygma (lineage 4a) was recovered as sister to the rest of the core Halimedaceae (except Halimedaceae). Boodleopsis sp. H.0758 (Lineage 1) was recovered now as sister to Caulerpaceae. In spite of the incongruent topologies in the core Halimedaceae, the monophyly of the Halimedaceae, Caulerpaceae, Pseudocodiaceae, and lineage 3 still stands.

Incongruent topologies between chloroplast and $18 \mathrm{~S}$ phylogenies were observed at the family level in suborders Bryopsidineae and Halimedineae. Chloroplast genome phylogenies generally gave better support for the relationships of families within the two suborders than the $18 \mathrm{~S}$ phylogenies. This is especially true in the suborder Halimedineae.

\section{Discussion}

Our analyses of a chloroplast multi-gene dataset including many previously unsequenced taxa generated several new insights into the phylogenetic history of the 
Bryopsidales. Our results have significant taxonomic implications, and here we propose a new classification system based on them.

All phylogenetic inferences using different models on all three datasets (partitioned and unpartitioned analyses of both amino acid and nucleotide data) recovered several early-branching lineages in Bryopsidineae and Halimedineae. At the highest taxonomic level, the relationships among suborders inferred in this study (Ostreobineae sister to Bryopsidineae + Halimedineae) concur with the results from previous studies (Cremen et al., 2018; Marcelino et al., 2016; Verbruggen et al., 2017). Despite the consistent recovery of the three suborders in our ML trees, the inclusion of Pseudobryopsis in our datasets did suggest the situation might be slightly more complex. The inclusion of this taxon reduced support for the monophyly of Bryopsidineae compared to previous studies on smaller datasets (Cremen et al., 2018; Marcelino et al., 2016; Verbruggen et al., 2017), and a closer investigation of the bootstrap trees showed that this taxon branched as sister to Ostreobineae for some of the resampled datasets. Because we had access to only a single species of the Pseudobryopsis-Trichosolen complex, the branch leading to this taxon is quite long, which may result in its placement being more uncertain. Even though the $18 \mathrm{~S}$ data suggests that Pseudobryopsis sits firmly within the Bryopsidineae, additional sampling in this group would be useful in future work to establish the most reliable position of this taxon in chloroplast phylogenies.

In the suborder Bryopsidineae, the Bryopsidaceae was recovered as sister to Derbesiaceae + Codiaceae, similar to a $\mathrm{ML}$ analyses inferred from a $r b c \mathrm{~L}+t u f \mathrm{~A}$ alignment with large taxon sampling in the Bryopsidineae (Leliaert et al., 2014). 
Conversely, cladistic analyses using morphological and anatomical features suggested a sister relationship between Bryopsidaceae and Derbesiaceae based on common features such as uniaxial morphology and sporic meiosis, separating them from Codiaceae (Vroom et al., 1998). Another study using maximum parsimony (MP) analysis based on $r b c \mathrm{~L}$ gene also inferred a sister relationship between Bryopsidaceae and Derbesiaceae but with low bootstrap support (60\%) (Lam and Zechman, 2006). In contrast, our 18S phylogeny was inconclusive about the relationships between these families (Bryopsidaceae + Codiaceae with $44 \%$ bootstrap support), and previous multigene trees recovered the Codiaceae as sister to Bryopsidaceae with strong support (81\% bootstrap, 1.00 BPP) (Verbruggen et al., 2009a).

Our chloroplast and 18S phylogenetic analyses showed for the first time the placement of the genus Lambia antarctica as an early-branching lineage sister to the rest of the Bryopsidaceae. The species was originally described as Derbesia antarctica by Skottsberg (1953), but Delépine (1967) noted that it has features such as chloroplast structure that are more similar to Codium. Like Bryopsis, the species is isogamous, but the thallus does not have the feather-like branching pattern and it lacks pyrenoids in the chloroplasts, both typical for Bryopsis (Delépine 1967). Based on this mismatch of features with other genera, the genus Lambia was established, but its relationship to other genera remained unclear until now. Our study also confirms the sister relationship of Pseudoderbesia and Bryopsis as inferred in an earlier study based on $r b c \mathrm{~L}$ and tufA by Leliaert et al. (2014). The genus Bryopsidella, not included in our analyses, has also been classified in the Bryopsidaceae but phylogenetic studies based on $r b c \mathrm{~L}$ or $r b c \mathrm{~L}+t u f \mathrm{~A}$ recovered it in the Derbesiaceae, sister to Pedobesia (Verbruggen et al., 2009a; Woolcott et al., 2000) or sister the rest 
of the Derbesiaceae (Leliaert et al. 2014). Bryopsidella is morphologically similar to Bryopsis, Pseudoderbesia, and Pseudobryopsis in their gametophyte stage by having branched prostrate siphons and upright siphons. The sporophytic thallus of Bryopsidella on the other hand resembles that of Derbesia by having branched interwoven siphons, which are sometimes anchored by rhizoids.

The separate phylogenetic position of Pseudobryopsis hainanensis within the Bryopsidineae suggests that it deserves recognition at the family level. Pseudobryopsis has been traditionally classified in the Bryopsidaceae and is morphologically similar to Bryopsis in having a central axis with numerous lateral siphon branches termed pinnules. They differ in their fertile state - Pseudobryopsis has been reported to bear specialized gametangia (Henne and Schnetter, 1999) while in Bryopsis the gametes are formed in unmodified pinnules. Our phylogenies show Pseudobryopsis hainanensis as a distinctly separate lineage from other members of Bryopsidaceae. From a taxonomic perspective, one option would be to reduce Bryopsidineae into a single family with the existing families and Pseudobryopsis as separate tribes. However, since Pseudobryopsis is clearly distinct from the other three existing families based on chloroplast genome phylogeny, we propose to erect a new family for Pseudobryopsis and retain the other existing bryopsidinean families in their current taxonomic status.

In the suborder Halimedineae, the sister relationship between the family Dichotomosiphonaceae and the core Halimedineae based on chloroplast genome phylogenies concurs with the results from previous phylogenetic studies using smaller datasets (Curtis et al., 2008; Verbruggen et al., 2009a). Cladocephalus, which is not 
included in our analyses, most likely also belongs to this lineage, and is probably related to Avrainvillea based on shared morphological and ultrastructural features (Roth and Friedmann 1987). The Caulerpaceae was inferred to be the sister lineage to the remaining core Halimedineae. This relationship was already suggested in previous studies also with high support (Leliaert et al., 2014; Verbruggen et al., 2009a). In contrast, our $18 \mathrm{~S}$ phylogeny recovered Halimedaceae as sister to the remaining members of the core Halimedineae, but the low bootstrap support (57\%) suggests the 18S data are inconclusive.

Among the new lineages of core Halimedineae recovered from the chloroplast phylogenies, one contains Callipsygma wilsonis and Rhipiliopsis peltata (lineage 4). This is an unexpected relationship, considering that Callipsygma is traditionally placed in the Udoteaceae (Womersley, 1984) and Rhipiliopsis in Rhipiliaceae (Dragastan et al., 1997). Womersley (1984) already noted some differences in siphon structure between Callipsygma wilsonis with other members of Udoteaceae and noted similarities with Rhipiliopsis, including segmented siphons and lateral attachment of segments. However, the features that Womersley noted on Callipsygma such as moniliform, ovoid segments of the filaments with perforate end walls and the laterally attached segments are not found in Rhipiliopsis peltata but rather in Rhipiliopsis robusta (not sampled in our study) (Womersley, 1984). It is interesting to note that Callipsygma, Rhipiliopsis peltata and Rhipiliopsis robusta are usually found in lowlight habitats such as heavily shaded pools or deeper waters up to $30 \mathrm{~m}$ deep. These observations taken together would suggest that Rhipiliopsis robusta is also a member of this lineage and that additional Rhipiliopsis species may also be recovered in this lineage when their chloroplast genomes get characterised. 
Two other genera currently classified in the Udoteaceae, Boodleopsis and Pseudochlorodesmis, were recovered as polyphyletic. Boodleopsis sp. H.0758 and Pseudochlorodesmis spp. HV01306a and HV01306c formed early-branching lineages (1 and 2, respectively) but some representatives of these genera were nested within lineage 3 (Figure 1, Supplementary FigureFigures S1-S3). These two genera exhibit very simple morphologies and are currently classified in the Udoteaceae, a family mostly containing species exhibiting complex morphologies and in some cases calcification. Cladistic analyses of morphological and anatomical characters placed Boodleopsis and Pseudochlorodesmis as sister taxa (albeit poorly supported) due to their uniaxial morphologies (Vroom et al., 1998). It has also been suggested that these taxa represent an alternate life cycle stage of morphologically complex taxa in the Halimedineae (i.e.: Pseudochlorodesmis-like life-stage in Halimeda tuna). While some of the more complex genera certainly have simpler life stages, our data and those of Verbruggen et al. (2009b) clearly show that there are also lineages of simple siphons that do not appear to have complex stages.

Boodleopsis forms green cushions or mats of entangled siphons on supralittoral to midlittoral rocks, mangrove roots, or muddy bottoms of shallow bays, often in sheltered and shaded locations (Taylor et al. 1953). Previous cladistic analyses based on morphological and anatomical characters included Boodleopsis where it was hypothesized that it would assume an early branching lineage within Halimedineae on the basis of traits they shared with Bryopsidineae - uniaxial morphology and stephanokontan zoospores (Vroom et al., 1998). However, Boodleopsis is also similar to the juvenile stages of Flabellia (F. petiolata) and Penicillus (P. capitatus) (Taylor 
et al., 1953). The hypothesis of relatedness derived from the morphological similarities were confirmed by an $r b c \mathrm{~L}$-based phylogeny where Boodleopsis was found to be related to Udoteaceae (Curtis et al., 2008). In our analyses, Boodleopsis was recovered in three very different positions in our phylogeny: one in lineage 1 , and two others in lineage 3, which also includes two species of the former Rhipiliaceae, a family characterized by blade-like thalli with interlinked siphons. The early branching nature of Boodleopsis in the core Halimedineae in general and in lineage 3 may be indicative that Boodleopsis-like morphology is an ancestral trait for the group, but denser taxon sampling and ancestral state estimation would be required to test this hypothesis.

Pseudochlorodesmis forms small, utterly simple thalli of sparingly branched siphons, and generally forms small turfs on hard substrata or coralline algae (Kraft 2007). Phylogenetic analyses based on tufA and $r b c \mathrm{~L}$ genes recovered the genus in two separate lineages - one forming an early-branching lineage in the core Halimedineae and the other at the base of the Rhipiliaceae (our lineage 3) (Verbruggen et al., 2009b). Recovering Pseudochlorodesmis in several early-branching lineages in our study not only concurs with the results of Verbruggen et al. (2009b) and other studies (Marcelino and Verbruggen, 2016; Sauvage et al., 2016; Verbruggen and Schils, 2012) but it further emphasizes their cryptic diversity. Our sample was taken from one clump but as we were analysing the data it turned out that from this tiny population, we obtained three different species that are very divergent from each other. It seems highly likely that targeted collections of these-simple morphologically simple siphonous turf-formers will further increase their known biodiversity. 
In the light of our phylogenetic results, in particular the disintegration of Rhipiliaceae and Udoteaceae, it is clear that a new classification scheme for the Halimedineae is needed. There are currently six recognized families in the suborder - Caulerpaceae, Dichotomosiphonaceae, Halimedaceae, Pseudocodiaceae, Rhipiliaceae, and Udoteaceae, of which three are monogeneric. Since the monophyletic nature of Dichotomosiphonaceae and Caulerpaceae has been established with confidence, they can be retained as they are. For the other families and new lineages inferred from our analyses, several scenarios for taxonomic change are possible. First, we could opt to erect new families for the currently nameless lineages (Supplementary Figure S5a). Second, we could merge lineage 4 (Callipsygma + Rhipiliopsis peltata) with the Halimedaceae and erect new families for the lineages of Boodleopsis sp. H.0758 and Pseudochlorodesmis spp. HV01306a and HV01306c. In doing so, the definitions of family Rhipiliaceae and Halimedaceae would have to be extended to accommodate Pseudochlorodesmis + Boodleopsis and Callipsygma + Rhipiliopsis peltata, respectively (Supplementary Figure S5b). Third, we could merge the families Pseudocodiaceae, Rhipiliaceae, Udoteaceae into a wider definition of Halimedaceae and designate the seven lineages as tribes (Figure 1).

The first two options would result in a proliferation of monogeneric families in the core Halimedineae, a situation that is not desirable from a taxonomic standpoint. Thus we propose to go with the third option as a practical solution. This classification scheme allows for a well circumscribed and firmly monophyletic Halimedaceae containing several higher-level clades, some of which contain only one genus (e.g. lineage 5) and others with multiple genera (e.g. lineage 7), which can be defined at the tribe level. At the same time it will allow taxonomists working on specific 
families of the previous classification framework (Halimedaceae s.s., Rhipiliaceae, Pseudocodiaceae and Udoteaceae) a point of reference for their groups that will now be designated as tribes, albeit with some modifications in the case of Rhipiliaceae and Udoteaceae.

In our proposal, the suborder Halimedineae is composed of three families: Dichotomosiphonaceae, Caulerpaceae, and Halimedaceae. The morphological delineation of the Halimedaceae, currently a monogeneric family, therefore needs to be extended to accommodate the new tribes and the species included therein: HalimedineaeHalimedeae, Pseudocodieae $\overline{-}_{2}$ Rhipileae, Rhipiliopsideae, and Udoteae (Table 1).. We refrain from formally naming the lineages of Boodleopsis sp. H.0758 and Pseudochlorodesmis HV01306a and HV01306c because the type species (Boodleopsis siphonacea and Pseudochlorodesmis furcellata, respectively) were not included in our analyses, and since the two genera are polyphyletic, the uncertainty regarding the phylogenetic position of the types results in uncertainty regarding suitable tribe names for the lineages in our trees. In both cases a more thorough investigation needs to be done in order to fully resolve the distribution and diversity of these diminutive siphonous species in the Bryopsidales phylogeny and taxonomic decisions be made when type species can be included.

A tribe-level classification for Halimedineae has already been proposed by HillisColinvaux (1984), who subdivided the subfamily Caulerpoideae into three tribes (Caulerpeae, Avrainvilleae, Rhipileae) based on morphological and allelochemical features. The tribe-level classification that we are proposing here will be different from Hillis-Colinvaux (1984) in their genus composition and most will be delimited 
based on their phylogenetic position inferred from molecular data.

In addition to the proposed changes at the family and tribe level, we also propose a taxonomic change at the genus level for Rhipiliopsis profunda. The type species for Rhipiliopsis is Rhipiliopsis peltata, which in our phylogeny formed a new lineage with Callipsygma wilsonis. It follows then that Rhipiliopsis profunda, which is nested in Rhipileae, should be renamed. In this case, a previous name is available, as $R$. profunda was originally described as Johnson-sea-linkia profunda (Eiseman \& Earle 1983).

\section{Taxonomic treatment}

\subsection{Taxonomic proposal at family level}

Pseudobryopsidaceae, Cremen, Leliaert, West, Lam, Verbruggen, fam. nov.

Description: Siphonous thalli composed of central axis with numerous lateral branches. Gametes in specialized gametangia arising from the lateral filaments. Recognized based on its highly divergent nature in phylogenetic trees derived from chloroplast genome data, with the chloroplast genome of Pseudobryopsis hainanensis H.0703 serving as reference.

Type genus: Pseudobryopsis Berthold, 1904

Taxa included in our molecular analyses: Pseudobryopsis hainanensis C.K. Tseng

Halimedaceae Link, 1832 emend

Description: Recognized as a well-supported clade in phylogenetic analyses based on the chloroplast genome data. Thalli range from simple diminutive siphons to complex 
multi-axial structures, including both calcified and uncalcified species.

Automatically typified by Halimeda J.V.Lamouroux, 1812

Tribes included: Halimedeae, Pseudocodieae, Rhipileae,

RhipiliopsieaeRhipiliopsideae and Udoteae

\subsection{Taxonomic proposals at tribe level}

Halimedeae Konishi, 1961 emend

Description: Thalli siphonous, multiaxial, macroscopic, composed of numerous, calcified flat or terete segments connected by narrow uncalcified nodes. Segments composed of filamentous medulla and cortex of inflated utricles, while the nodes are composed of parallel medullary siphons.

Type and only genus: Halimeda J.V.Lamouroux, 1812

Pseudocodieae Cremen, Leliaert, West, Lam, Verbruggen, trib nov.

Description: Thalli siphonous, multiaxial, macroscopic, uncalcified, dichotomously branched cylindrical tubes composed of a medulla of interwoven siphons that form a single layer of peripheral utricles.

Type and only genus: Pseudocodium Weber-van Bosse, 1896

Rhipileae L.Hillis-Collinvaux, 1984 emend.

Description: Thalli siphonous, morphologically variable ranging from uniaxial diminutive siphons to multiaxial thalli forming fan-shaped blades composed of interwoven irregularly or dichotomously branched siphons interconnected by tenacula or lateral adhesion papillae.

Type genus: Rhipilia Kützing, 1858 
Taxa included in our molecular analyses:

Boodleopsis pusilla (Collins) W.R.Taylor, A.B.Joly, \& Bernatowicz 1953, Boodleopsis sp. (GenBank: MH591102), Johnson-sea-linkia profunda Eiseman \& S.A.Earle 1983, Pseudochlorodesmis sp. (GenBank: MH591096), Rhipilia penicilloides A.D.E.N'Yeurt \& D.W.Keats 1997.

Note: Rhipileae was originally erected based on the lack of calcification and absence of rhizomatous habit. It originally included Boodleopsis, Callipsygma, Chlorodesmis, Johnson-sea-linkia, Pseudochlorodesmis, Rhipilia, Rhipiliopisis, and Flabellaria (Udotea) petiolata (Hillis-Collinvaux 1984).

Rhipiliopsideae Cremen, Leliaert, West, Lam, Verbruggen, trib nov.

Description: Thallus siphonous, macroscopic, simple with distinct stipe and lamina or complanately branched with upper branches bearing alternate, distichous, to flabellate branch systems. Filaments elongated with regular constricted segments at times laterally attached and with perforate end walls; or slender filaments that are dichotomously branched with equal constrictions above the dichotomy, attached laterally by circular rings or by short protrusions from adjacent filaments.

Type genus: Rhipiliopsis A.Gepp \& E.S.Gepp 1911

Taxa included in our molecular analyses:

Callipsygma wilsonis J.Agardh 1877, Rhipiliopsis peltata (J.Agardh) A.Gepp \& E.S.Gepp 1911

Udoteae Konishi 1961, emend

Description: Thallus siphonous, macroscopic, morphologically variable ranging from simple tufts of branched siphons, simple stalked blades to more complex corticated 
blades with calcified thalli.

Type genus: Udotea J.V.Lamourox 1812

Taxa included in our molecular analyses:

Chlorodesmis fastigiata (C.Agardh) S.C.Ducker 1969, Flabellia petiolata (Turra)

Nizamuddin 1987, Tydemania expeditionis Weber-van Bosse 1901, Udotea argentea

Zanardini, Udotea flabellum (J.Ellis \& Solander) M. Howe 1904, Udotea sp.

(GenBank: MH591111).

\subsection{Reinstatement of Johnson-sea-linkia profunda}

This deep-water species was first collected using the submersible Johnson-Sea-Link on 16 April 1975 at depths of 60 to $120 \mathrm{~m}$ in various locations in the Bahamas, and later observed on a 153 m deep vertical cliff (Eiseman and Earle, 1983). Eiseman and Earle (1983) noted that the species resembles Rhipiliopsis in some features but lacks the leucoplasts and the thallus is not distinctly funnel-form nor are the fronds net-like. Norris and Olsen (1991) transferred it to Rhipiliopsis following Kraft's (1986) broader generic definition of the genus, which included different kinds of lateral cohesions including types with or without papillae. Norris and Olsen (1991) argued its lateral cohesions along the blade's parallel filaments and perpendicular cross filaments did not distinguish it as a separate genus.

Our proposal to reinstate the name Johnson-sea-linkia profunda is made based on our phylogenetic analyses, as it no longer clusters with Rhipiliopsis peltata, the type species of the genus. 


\section{Conclusions and perspectives}

The chloroplast-genome based phylogenies presented here gave good support for the major lineages inferred in our phylogenies. Increased taxon sampling helped resolve the taxonomic placement of Pseudobryopsis and Lambia in Bryopsidineae. In Halimedineae, several early-branching lineages were inferred, several of which were unknown. Our phylogenetic analyses resolved the placement of the families Dichotomosiphonaceae and Caulerpaceae with respect to the remaining Halimedineae, but relationships between the remaining families in this suborder remain poorly resolved. Our proposal to establish tribes under the broader definition of Halimedaceae is a more stable taxonomic solution. The proliferation of earlybranching lineages in the core Halimedineae outside the traditionally recognized families highlights the underestimated higher-level taxonomic diversity of the group. As most of the early-branching lineages inferred were made up of species with diminutive siphons, morphological delineation of these lineages may not be possible. Although chloroplast genome data were able to resolve tribe-level relationships in other algal groups such as the Rhodomelaceae (Díaz-Tapia et al., 2017), this approach might not hold true for rapidly diversifying lineages as seen in the core Halimedineae. Further improvements can be made in the near future to better resolve the phylogeny of the order. As most of the early-branching lineages inferred from our phylogeny included taxa with very simple morphologies, including additional species with simple morphologies in future studies may improve relationships in the Halimedineae. Likewise, addition of other Pseudobryopsis and Trichosolen species could break-up the long branch in the Bryopsidineae.

The taxonomic proposals in our study were mainly based on chloroplast genome 
phylogenies due to better resolutions, as the nuclear $18 \mathrm{~S}$ phylogeny was inconclusive especially in the core Halimedineae. This is perhaps owned to the fact that in our $18 \mathrm{~S}$

phylogeny, there were far fewer representatives in the core Halimedineae compared to the chloroplast phylogenies. Adding more taxa and including additional nuclear markers in the future could confirm the results of our chloroplast genome-based phylogenies.

\section{Acknowledgements}

This work was supported by the Australian Biological Resources Study (RFL213-08), the Australian Research Council (DP150100705), the University of Melbourne (MIRS/MIFRS to MCMC), the Holsworth Wildlife Research Endowment, and the National Science Foundation (GRAToL 10136495) to JLB. We used computational resources from Melbourne Bioinformatics (project UOM0007) and the Nectar Research Cloud, a collaborative Australian research platform supported by the National Collaborative Research Infrastructure Strategy (NCRIS) and the Alabama Supercomputer Authority. We thank Claude Payri for facilitating the fieldwork in PNG; Stephanie Muller (CSHL), Roger Nielsen (GGF), and Ting-ting Wang (Novogene) for the assistance they provided during the sequencing of the samples; Tim Entwisle and Andrew Drinnan for helpful discussions on classification schemes; Mike Guiry for the nomenclatural advice; the people from Verbruggen lab especially Margaret Brookes, Joana Costa, Pilar Diaz, Chirs Jackson, and Vanessa Marcelino, for the fruitful discussions. The authors declare no conflict of interest. 


\section{References:}

Abascal, F., Zardoya, R., Telford, M.J., 2010. TranslatorX: multiple alignment of nucleotide sequences guided by amino acid translations. Nucleic Acids Res. 38, W7-W13. https://doi.org/10.1093/nar/gkq291

Bankevich, A., Nurk, S., Antipov, D., Gurevich, A.A., Dvorkin, M., Kulikov, A.S., Lesin, V.M., Nikolenko, S.I., Pham, S., Prjibelski, A.D., Pyshkin, A. V., Sirotkin, A. V., Vyahhi, N., Tesler, G., Alekseyev, M.A., Pevzner, P.A., 2012. SPAdes: A New Genome Assembly Algorithm and Its Applications to SingleCell Sequencing. J. Comput. Biol. 19, 455-477. https://doi.org/10.1089/cmb.2012.0021

Castresana J. 2000. Selection of conserved blocks from multiple alignments for their use in phylogenetic analysis. Mol Biol Evol. 17(4):540-552.

Cocquyt, E., Gile, G.H., Leliaert, F., Verbruggen, H., Keeling, P.J., De Clerck, O., 2010. Complex phylogenetic distribution of a non-canonical genetic code in green algae. BMC Evol. Biol. 10, 327. https://doi.org/10.1186/1471-2148-10327

Costa, J.F., Lin, S., Macaya, E.C., Fernández-García, C., Verbruggen, H., 2016. Chloroplast genomes as a tool to resolve red algal phylogenies: a case study in the Nemaliales. BMC Evol. Biol. 16, 205. https://doi.org/10.1186/s12862-016$0772-3$

Cremen, M.C.M., Huisman, J.M., Marcelino, V.R., Verbruggen, H. 2016. Taxonomic revision of Halimeda (Bryopsidales, Chlorophyta) in south-western Australia. Aust. Sys. Bot. 29: 41-54. https://doi.org/10.1071/SB15043.

Cremen, M.C.M., Leliaert, F., Marcelino, V.R., Verbruggen, H., 2018. Large diversity of nonstandard genes and dynamic evolution of chloroplast genomes in 
siphonous green algae (Bryopsidales, Chlorophyta). Genome Biol. Evol. 10, 1048-1061. https://doi.org/10.1093/gbe/evy063

Curtis, N.E., Dawes, C.J., Pierce, S.K., 2008. Phylogenetic analysis of the large subunit rubisco gene supports the exclusion of Avrainvillea and Cladocephalus from the Udoteaceae (Bryopsidales, Chlorophyta). J. Phycol. 44, 761-767. https://doi.org/10.1111/j.1529-8817.2008.00519.x

Darriba, D., Taboada, G.L., Doallo, R., Posada, D., 2012. jModelTest 2: more models, new heuristics and parallel computing. Nat. Methods 9, 772-772. https://doi.org/10.1038/nmeth.2109

Darriba, D., Taboada, G.L., Doallo, R., Posada, D., 2011. ProtTest 3: fast selection of best-fit models of protein evolution. Bioinformatics 27, 1164-1165. https://doi.org/10.1093/bioinformatics/btr088

De Clerck, O., Verbruggen, H., Huisman, J.M., Faye, E.J., Leliaert, F., Schils, T., Coppejans, E., 2008. Systematics and biogeography of the genus Pseudocodium (Bryopsidales, Chlorophyta), including the description of $P$. natalense sp. nov. from South Africa. Phycologia 47, 225-235. https://doi.org/10.2216/07-79.1 del Campo, J., Pombert, J.-F., Šlapeta, J., Larkum, A., Keeling, P.J., 2017. The 'other' coral symbiont: Ostreobium diversity and distribution. ISME J. 11, 296-299. https://doi.org/10.1038/ismej.2016.101

Delépine, R., 1967. Sur un nouveau genre de Chlorophycées antarctiques, Lambia. Compte Rendu Hebdomadaire des Séances de l'Académie des Sciences. Paris. Série D 264(D): 1410-1413.

Díaz-Tapia, P., Maggs, C.A., West, J.A., Verbruggen, H., 2017. Analysis of chloroplast genomes and a supermatrix inform reclassification of the Rhodomelaceae (Rhodophyta). J. Phycol. 937, 920-937. 
https://doi.org/10.1111/jpy.12553

Dragastan, O.N., Richter, D.K., Kube, B., Popa, M., Sarbu, A., Ciugulea, I., 1997. A new family of paleo-mesozoic calcareous green siphons-algae (Order Bryopsidales, Class Bryosidophyceae, Phylum Siphonophyta). Rev. Española Micropaleontol. 29, 69-135.

Draisma, S.G.A., van Reine, W.F.P., Sauvage, T., Belton, G.S., Gurgel, C.F.D., Lim, P.-E., Phang, S.-M., 2014. A re-assessment of the infra-generic classification of the genus Caulerpa (Caulerpaceae, Chlorophyta) inferred from a time-calibrated molecular phylogeny. J. Phycol. 50, 1020-1034. https://doi.org/10.1111/jpy.12231

Drew, E.A., Abel, K.M., 1995. V. Effect of temperature on chloroplast migration in this siphonous green alga. Biol. Rhythm Res. 26, 48-54. https://doi.org/10.1080/09291019509360323

Drew, E.A., 1983. Halimeda biomass, growth rates and sediment generation on reefs in the central great barrier reef province. Coral Reefs J. Int. Soc. Reef Stud. 2, 101-110. https://doi.org/10.1007/BF02395280

Eiseman, N.J., Earle, S.A., 1983. Johnson-sea-linkia profunda, a new genus and species of deep-water Chlorophyta from the Bahama Islands. Phycologia 22, 16.

Famà, P., Wysor, B., Kooistra, W.H.C.F., Zuccarello, G.C., 2002. Molecular phylogeny of the genus Caulerpa (Caulerpales, Chlorophyta) inferred from chloroplast tufA gene. J. Phycol. 38, 1040-1050. https://doi.org/10.1046/j.15298817.2002.t01-1-01237.x

Fang, L., Leliaert, F., Novis, P.M., Zhang, Z., Zhu, H., Liu, G., Penny, D., Zhong, B., 2018. Improving phylogenetic inference of core Chlorophyta using chloroplast 
sequences with strong phylogenetic signals and heterogeneous models. Mol. Phylogenet. Evol. 127, 248-255.

https://doi.org/https://doi.org/10.1016/j.ympev.2018.06.006

Fučíková, K., Leliaert, F., Cooper, E.D., Škaloud, P., D’Hondt, S., De Clerck, O., Gurgel, C.F.D., Lewis, L.A., Lewis, P.O., Lopez-Bautista, J.M., Delwiche, C.F., Verbruggen, H., 2014. New phylogenetic hypotheses for the core Chlorophyta based on chloroplast sequence data. Front. Ecol. Evol. 2, 1-12.

https://doi.org/10.3389/fevo.2014.00063

Guindon, S., Gascuel, O., 2003. A simple, fast, and accurate algorithm to estimate large phylogenies by maximum likelihood. Syst. Biol. 52, 696-704. https://doi.org/10.1080/10635150390235520

Guiry, M.D., Guiry, G.M., 2017. AlgaeBase. World-wide electronic publication, National University of Ireland, Galway. http://www.algaebase.org.

Henne, K.-D., Schnetter, R., 1999. Revision of the Pseudobryopsis/Trichosolen complex (Bryopsidales, Chlorophyta) based on features of gametangial behavior and chloroplasts. Phycologia 38, 114-127. https://doi.org/10.2216/i0031-8884$38-2-114.1$

Hillis-Colinvaux, L.W. 1984. Systematics of the Siphonales. In: Irvine D. John D. Eds. Systematics of the Green Algae. The Systematics Association Special Volume 27. London: Academic Press. p. 271-296.

Hillis, L.W., Engman, J.A., Kooistra, W.H.C.F., 1998. Morphological and molecular phylogenies of Halimeda (Chlorophyta, Bryopsidales) identify three evolutionary lineages. J. Phycol. 34, 669-681. https://doi.org/10.1046/j.15298817.1998.340669.x

Kalyaanamoorthy, S., Minh, B.Q., Wong, T.K.F., Von Haeseler, A., Jermiin, L.S., 
2017. ModelFinder: Fast model selection for accurate phylogenetic estimates.

Nat. Methods 14, 587-589. https://doi.org/10.1038/nmeth.4285

Katoh, K., Standley, D.M., 2013. MAFFT multiple sequence alignment software version 7: Improvements in performance and usability. Mol. Biol. Evol. 30, 772780. https://doi.org/10.1093/molbev/mst010

Kerswell, A.P., 2006. Global biodiversity patterns of benthic marine algae. Ecology $87,2479-2488$.

Klein, J., Verlaque, M., 2008. The Caulerpa racemosa invasion: A critical review. Mar. Pollut. Bull. 56, 205-225. https://doi.org/10.1016/j.marpolbul.2007.09.043

Kooistra, W.H.C.F., 2002. Molecular phylogenies of Udoteaceae (Bryopsidales, Chlorophyta) reveal nonmonophyly for Udotea, Penicillus and Chlorodesmis. Phycologia 41, 453-462. https://doi.org/10.2216/i0031-8884-41-5-453.1

Kornmann, P., Sahling, P.H., 1980. Ostreobium quekettii (Codiales, Chlorophyta). Helgoländer Meeresuntersuchungen 34, 115-122. https://doi.org/10.1007/BF01984034

Kraft, G.T. 2007. Algae of Australia: Marine Benthic Algae of Lord Howe Island and the SOuthern Great Barrier Reef, 1. Green Algae. ABRS, Canberra; CSIRO Publishing, Melbourne.

Kraft, G.T. 1986. The green algal genera Rhipiliopsis A. \& E.S. Gepp and Rhipiliella gen. nov. (Udoteaceae, Bryopsidales) in Australia and the Philippines. Phycologia 25: 47-72.

Krellwitz, E.C., Kowallik, K. V., Manos, P.S., 2001. Molecular and morphological analyses of Bryopsis (Bryopsidales, Chlorophyta) from the western North Atlantic and Caribbean. Phycologia 40, 330-339. https://doi.org/10.2216/i00318884-40-4-330.1 
Lam, D.W., Lopez-Bautista, J.M., 2016. Complete chloroplast genome for Caulerpa racemosa and compartive analyses of siphonous green seaweeds plastomes . Cymbella 2.

Lam, D.W., Zechman, F.W., 2006. Phylogenetic analyses of the Bryopsidales (Ulvophyceae, Chlorophyta) based on RUBISCO large subunit gene sequences. J. Phycol. 42, 669-678. https://doi.org/10.1111/j.1529-8817.2006.00230.x

Leliaert, F., Lopez-Bautista, J.M., 2015. The chloroplast genomes of Bryopsis plumosa and Tydemania expeditiones (Bryopsidales, Chlorophyta): compact genomes and genes of bacterial origin. BMC Genomics 16, 204. https://doi.org/10.1186/s12864-015-1418-3

Leliaert, F., Verbruggen, H., D’Hondt, S., López-Bautista, J.M., De Clerck, O., 2014. The forgotten genus Pseudoderbesia (Bryopsidales, Chlorophyta). Cryptogam. Algol. 35, 207-219. https://doi.org/10.7872/crya.v35.iss3.2014.207

Lemieux, C., Otis, C., Turmel, M., 2014a. Chloroplast phylogenomic analysis resolves deep-level relationships within the green algal class Trebouxiophyceae. BMC Evol. Biol. 14, 211. https://doi.org/10.1186/s12862-014-0211-2

Lemieux, C., Otis, C., Turmel, M., 2014b. Six newly sequenced chloroplast genomes from prasinophyte green algae provide insights into the relationships among prasinophyte lineages and the diversity of streamlined genome architecture in picoplanktonic species. BMC Genomics 15, 857. https://doi.org/10.1186/1471$2164-15-857$

Lemieux, C., Vincent, A.T., Labarre, A., Otis, C., Turmel, M., 2015. Chloroplast phylogenomic analysis of chlorophyte green algae identifies a novel lineage sister to the Sphaeropleales (Chlorophyceae). BMC Evol. Biol. 15, 264. https://doi.org/10.1186/s12862-015-0544-5 
Li, D., Liu, C.M., Luo, R., Sadakane, K., Lam, T.W., 2014. MEGAHIT: An ultra-fast single-node solution for large and complex metagenomics assembly via succinct de Bruijn graph. Bioinformatics 31, 1674-1676.

https://doi.org/10.1093/bioinformatics/btv033

Lin, H.H., Liao, Y.C., 2016. Accurate binning of metagenomic contigs via automated clustering sequences using information of genomic signatures and marker genes. Sci. Rep. 6, 12-19. https://doi.org/10.1038/srep24175

Lü, F., Xü, W., Tian, C., Wang, G., Niu, J., Pan, G., Hu, S., 2011. The Bryopsis hypnoides plastid genome: multimeric forms and complete nucleotide sequence. PLoS One 6, e14663. https://doi.org/10.1371/journal.pone.0014663

Marcelino, V.R., Cremen, M.C.M., Jackson, C.J., Larkum, A.A.W., Verbruggen, H., 2016. Evolutionary dynamics of chloroplast genomes in low light: A case study of the endolithic green alga Ostreobium quekettii. Genome Biol. Evol. 8, 29392951. https://doi.org/10.1093/gbe/evw206

Marcelino, V.R., Verbruggen, H., 2016. Multi-marker metabarcoding of coral skeletons reveals a rich microbiome and diverse evolutionary origins of endolithic algae. Scientific Reports 6: 31508. https://www.doi.org/10.1038/srep31508.

Meinesz, A., Belsher, T., Thibaut, T., Antolic, B., Mustapha, K. Ben, Boudouresque, C.F., Chiaverini, D., Cinelli, F., Cottalorda, J.M., Djellouli, A., El Abed, A., Orestano, C., Grau, A.M., Ivesa, L., Jaklin, A., Langar, H., Massuti-Pascual, E., Peirano, A., Tunesi, L., De Vaugelas, J., Zavodnik, N., Zuljevic, A., 2001. The introduced green alga Caulerpa taxifolia continues to spread in the Mediterranean. Biol. Invasions 3, 201-210.

Noris, J.N., Olsen, J.L. 1991. Deep-water green algae from the Bahamas, inbcluding 
Caldophora vandenhoekii sp. nov. (Cladophorales). Phycologia 30: 315-328.

Oliveira, M.C., Repetti, S.I., Iha, C., Jackson, C.J., Díaz-Tapia, P., Lubiana, K.M.F., Cassano, V., Costa, J.F., Cremen, M.C.M., Marcelino, V.R., Verbruggen, H., 2018. High-throughput sequencing for algal systematics. Eur. J. Phycol. 00, 117. https://doi.org/10.1080/09670262.2018.1441446

Pauly, K., Jupp, B.P., de Clerck, O., 2011. Modelling the distribution and ecology of Trichosolen blooms on coral reefs worldwide. Mar. Biol. 158, 2239-2246. https://doi.org/10.1007/s00227-011-1729-0

Peng, Y., Leung, H.C.M., Yiu, S.M., Chin, F.Y.L., 2010. IDBA - A practical iterative De Bruijn graph de novo assembler, In: Lecture notes in Computer Science (Including Subseries Lecture Notes in Artificial Intelligence and Lecture Notes in Bioinformatics). https://doi.org/10.1007/978-3-642-12683-3_28

Roth, W.C., Friedmann, E. I., 1987. Ultrastructure of the siphonous green algae Avrainvillea and Cladocephalus. Phycologia 26:70-81.

Sauvage, T., Schmidt, W.E., Suda, S., Fredericq, S., 2016. A metabarcoding framework for facilitated survey of endolithic phototrophs with tufA. BMC Ecol. 16, 8. https://doi.org/10.1186/s12898-016-0068-x

Shavit, L., Penny, D., Hendy, M.D., Holland, B.R., 2007. The problem of rooting rapid radiations. Mol. Biol. Evol. 24, 2400-2411. https://doi.org/10.1093/molbev/msm178

Škaloud, P., Kalina, T., Nemjová, K., De Clerck, O., Leliaert, F., 2013. Morphology and phylogenetic position of the freshwater green microalgae Chlorochytrium (Chlorophyceae) and Scotinosphaera (Scotinosphaerales, ord. nov., Ulvophyceae). J. Phycol. 49, 115-129. https://doi.org/10.1111/jpy.12021 Skottsberg, C., 1953. On two collections of Antarctic marine algae. Arkiv für 
Botanik, ser. 2(2): 531-566.

Solymosi, K., 2013. Plastid structure, diversification and interconversions I. Algae.

Curr. Chem. Biol. 6, 167-186. https://doi.org/10.2174/2212796811206030002

Stamatakis, A., 2014. RAxML version 8: a tool for phylogenetic analysis and postanalysis of large phylogenies. Bioinformatics 30, 1312-1313.

https://doi.org/10.1093/bioinformatics/btu033

Taylor, W.R., Joly, A.B., Bernatowicz, A.J., 1953. The relation of Dichotomosiphon pusillus to the algal genus Boodleopsis. Michigan Acad. Sci. Arts Lett. 38, 97107.

Trowbridge, C.D., 1995. Establishment of the green alga Codium fragile ssp. tomentosoides on New Zealand rocky shores: current distribution and invertebrate grazers. J. Ecol. https://doi.org/10.2307/2261177

Turmel, M., Brouard, J.S., Gagnon, C., Otis, C., Lemieux, C., 2008. Deep division in the chlorophyceae (Chlorophyta) revealed by chloroplast phylogenomic analyses. J. Phycol. 44, 739-750. https://doi.org/10.1111/j.15298817.2008.00510.x

Turmel, M., Otis, C., Lemieux, C., 2017. Divergent copies of the large inverted repeat in the chloroplast genomes of ulvophycean green algae. Sci. Rep. 7, 994. https://doi.org/10.1038/s41598-017-01144-1

Verbruggen, H., Ashworth, M., LoDuca, S.T., Vlaeminck, C., Cocquyt, E., Sauvage, T., Zechman, F.W., Littler, D.S., Littler, M.M., Leliaert, F., 2009a. A multi-locus time-calibrated phylogeny of the siphonous green algae. Mol. Phylogenet. Evol. 50, 642-653. https://doi.org/10.1016/j.ympev.2008.12.018

Verbruggen, H., Costa, J.F. 2015. The plastid genome of the red alga Laurencia. J. Phycol. 51: 586-589. https://doi.org/10.1111/jpy.12297. 
Verbruggen, H., Leliaert, F., Maggs, C. a, Shimada, S., Schils, T., Provan, J., Booth, D., Murphy, S., De Clerck, O., Littler, D.S., Littler, M.M., Coppejans, E., 2007. Species boundaries and phylogenetic relationships within the green algal genus Codium (Bryopsidales) based on plastid DNA sequences. Mol. Phylogenet. Evol. 44, 240-254. https://doi.org/10.1016/j.ympev.2007.01.009

Verbruggen, H., Marcelino, V.R., Guiry, M.D., Cremen, M.C.M., Jackson, C.J., 2017. Phylogenetic position of the coral symbiont Ostreobium (Ulvophyceae) inferred from chloroplast genome data. J. Phycol. 53, 790-803. https://doi.org/10.1111/jpy.12540

Verbruggen, H., Schils, T., 2012. Rhipilia coppejansii, a new coral reef-associated species from Guam (Bryopsidales, Chlorophyta). J. Phycol. 48, 1090-1098. https://doi.org/10.1111/j.1529-8817.2012.01199.x

Verbruggen, H., Vlaeminck, C., Sauvage, T., Sherwood, A.R., Leliaert, F., De Clerck, O., 2009b. Phylogenetic analysis of Pseudochlorodesmis strains reveals cryptic diversity above the family level in the siphonous green algae (Bryopsidales, Chlorophyta). J. Phycol. 45, 726-731. https://doi.org/10.1111/j.15298817.2009.00690.x

Vroom, P.S., Smith, C.M., 2003. Life without cells. Biologist 50, 222-226.

Vroom, P.S., Smith, C.M., Keeley, S.C., 1998. Cladistics of the Bryopsidales: A preliminary analysis. J. Phycol. 34, 351-360. https://doi.org/10.1046/j.15298817.1998.340351.x

Womersley, H.B.S., 1984. The marine benthic flora of Southern Australia. Part 1. South Australian Government Printing Division, Adelaide, South Australia. Woolcott, G.W., Knöller, K., King, R.J., 2000. Phylogeny of the Bryopsidaceae (Bryopsidales, Chlorophyta): cladistic analyses of morphological and molecular 
data. Phycologia 39, 471-481. https://doi.org/10.2216/i0031-8884-39-6-471.1

Wu, Y.W., Tang, Y.H., Tringe, S.G., Simmons, B.A., Singer, S.W., 2014. MaxBin: An automated binning method to recover individual genomes from metagenomes using an expectation-maximization algorithm. Microbiome 2, 1-18. https://doi.org/10.1186/2049-2618-2-26 
${ }^{*} \begin{aligned} & \text { Ostreobium sp. KY509314 } \\ & \text { Ostreobium quekettii LT593849 }\end{aligned}$

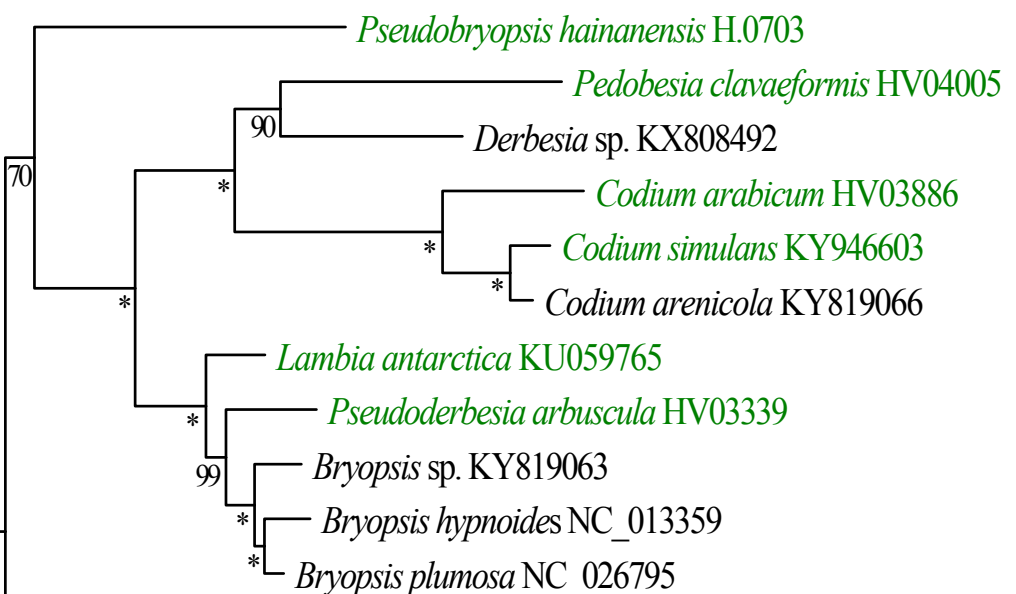

- Dichotomosiphon tuberosus Shimada1401

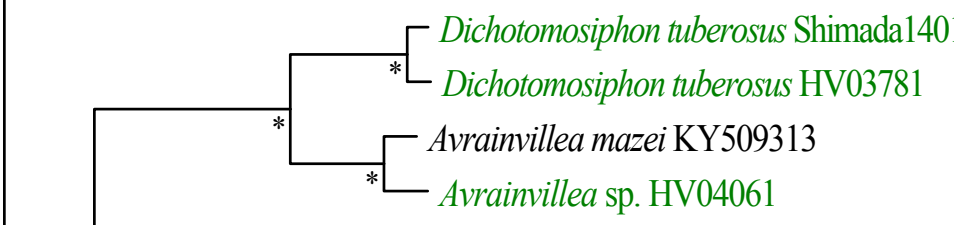

[ Caulerpa manorensis KY819068

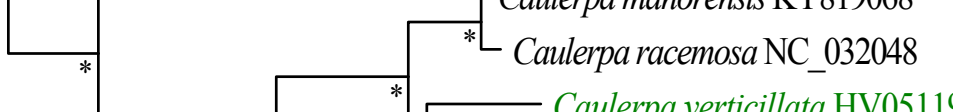

Core Halimedineae

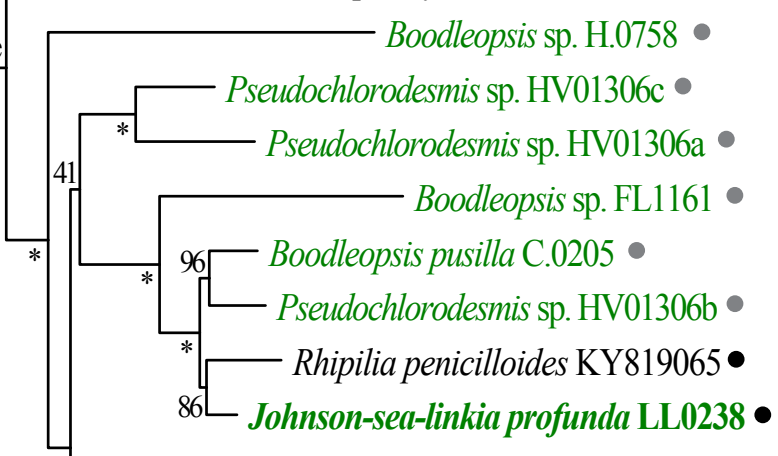

93 Callipsygma wilsonis HV03983

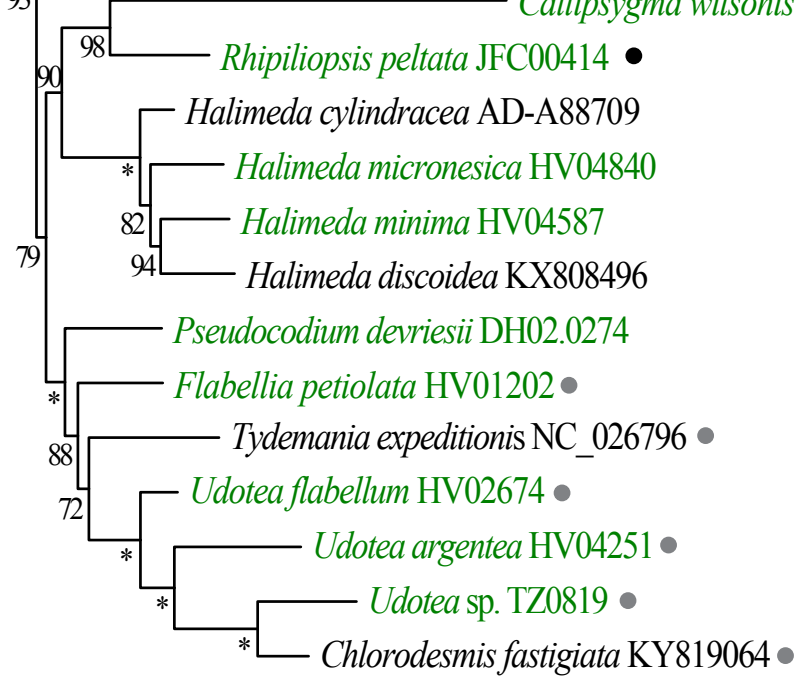

Ostreobiaceae

Pseudobryopsidaceae

Derbesiaceae

Codiaceae

Bryopsidaceae

Dichotomosiphonaceae

\section{Lineage $1 \quad$ CH T1 \\ Lineage 2 CH T2}

Halimedaceae

\section{Caulerpaceae}

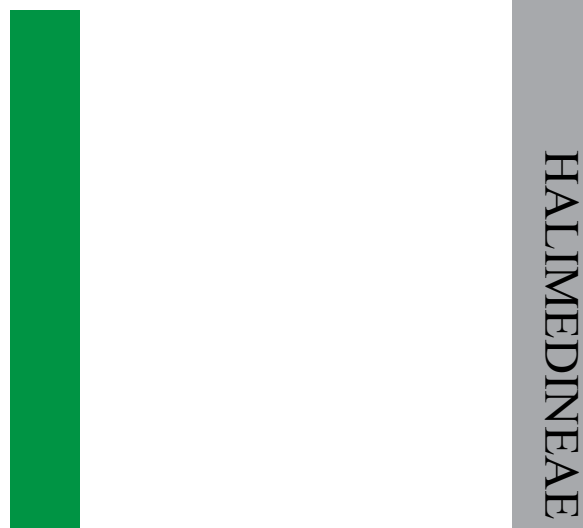

Lineage 3 Rhipileae

Lineage 4 Rhipiliopsideae

Lineage 5 Halimedeae

Lineage $6 \square$ Pseudocodieae

Lineage 7 Udoteae 


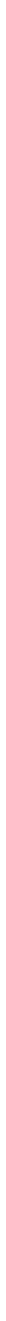

